\title{
Article \\ Mach 4 Simulating Experiment of Pre-Cooled Turbojet Engine Using Liquid Hydrogen
}

\author{
Hideyuki Taguchi *(D), Kenya Harada, Hiroaki Kobayashi, Motoyuki Hongoh, Daisaku Masaki \\ and Shunsuke Nishida (D)
}

Citation: Taguchi, H.; Harada, K.; Kobayashi, H.; Hongoh, M.; Masaki, D.; Nishida, S. Mach 4 Simulating Experiment of Pre-Cooled Turbojet Engine Using Liquid Hydrogen. Aerospace 2022, 9, 39. https:/ / doi.org/10.3390/aerospace9010039 Academic Editors: Sergey Leonov and Kojiro Suzuki

Received: 3 October 2021

Accepted: 10 January 2022

Published: 14 January 2022

Publisher's Note: MDPI stays neutral with regard to jurisdictional claims in published maps and institutional affiliations.

Copyright: (C) 2022 by the authors. Licensee MDPI, Basel, Switzerland. This article is an open access article distributed under the terms and conditions of the Creative Commons Attribution (CC BY) license (https:// creativecommons.org/licenses/by/ $4.0 /)$.
Japan Aerospace Exploration Agency, Tokyo 182-8522, Japan; harada.kenya@jaxa.jp (K.H.); kobayashi.hiroaki@jaxa.jp (H.K.); hongoh.motoyuki@jaxa.jp (M.H.); masaki.daisaku@jaxa.jp (D.M.); nishida.shunsuke@jaxa.jp (S.N.)

* Correspondence: taguchi.hideyuki@jaxa.jp; Tel.: +81-70-3117-7129

\begin{abstract}
This study investigated a pre-cooled turbojet engine for a Mach 5 class hypersonic transport aircraft. The engine was demonstrated under takeoff and Mach 2 flight conditions, and a Mach 5 propulsion wind tunnel test is planned. The engine is composed of a pre-cooler, a core engine, and an afterburner. The engine was tested under simulated Mach 4 conditions using an air supply facility. High-temperature air under high pressure was supplied to the engine components through an airflow control valve and an orifice flow meter, and liquid hydrogen was supplied to the pre-cooler and the core engine. The results confirmed that the starting sequence of the engine components was effective under simulated Mach 4 conditions using liquid hydrogen fuel. The pre-cooling effect caused no damage to the rotating parts of the core engine in the experiment.
\end{abstract}

Keywords: hypersonic; hydrogen; turbojet

\section{Introduction}

JAXA is investigating a design approach to a Mach 5 hypersonic passenger aircraft [1] (Figure 1), which could significantly reduce the flight time for intercontinental travel. The X-43A [2] flight experiment successfully demonstrated hypersonic flight with a scramjet engine. The following plans demonstrate the feasibility of hypersonic propulsion systems. JAXA focused on hypersonic propulsion systems as the key to successful hypersonic passenger aircraft and slated demonstrations of Mach 5 hypersonic technologies for 2025 [3].

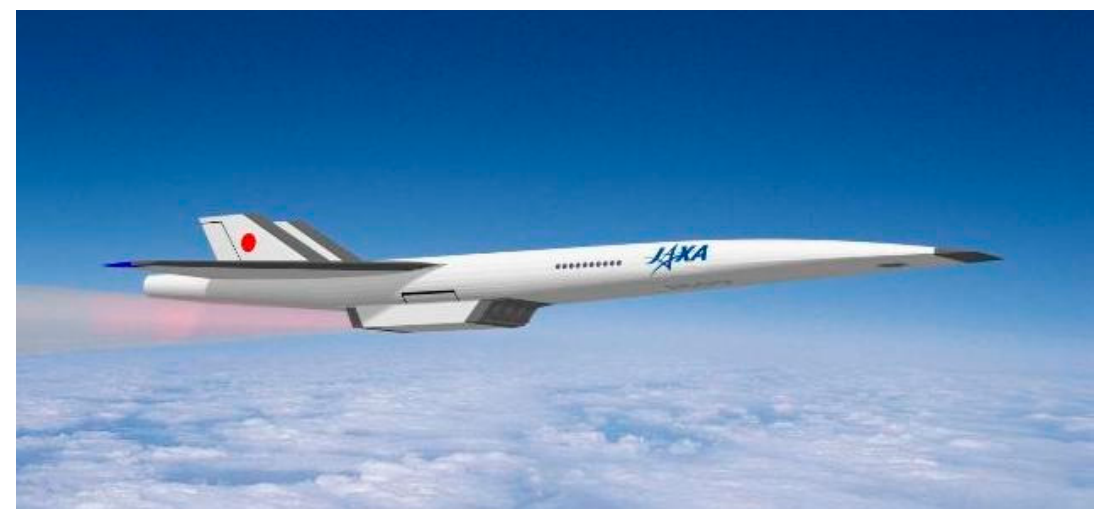

Figure 1. Hypersonic Passenger Aircraft.

JAXA designed and fabricated pre-cooled turbojets [4] that can accelerate an aircraft continuously from takeoff to Mach 5. This engine uses a heat exchanger to cool the hot incoming air during hypersonic flight. A pre-cooler is mounted in front of the turbojet core 
engine, and cryogenic liquid hydrogen is used as a coolant and fuel. The total temperature during a Mach 5 flight is around $1300 \mathrm{~K}$, but pre-cooling decreases the temperature to $600 \mathrm{~K}$, thermally protecting the core engine. The compressor power is reduced by pre-cooling, and the residual power can be used for propulsion via the exhaust gas.

The thrust performance of a pre-cooled turbojet was investigated using performance analyses [4]. A supersonic flight experiment at Mach 2 was conducted [5]. The vehicle, separated from a stratospheric balloon and accelerated to Mach 2 through free fall, demonstrated the operation of the pre-cooled turbojet and engine at Mach 2.

In this study, an experiment simulating a Mach 4 flight investigated the pre-cooled turbojet engine to confirm its high-temperature structural design and the engine starting sequence. Mach 4 conditions with a total temperature of $900 \mathrm{~K}$ were selected as the intermediate target to demonstrate the pre-cooling cycle using an existing hot air supply facility. Liquid hydrogen was used as fuel by the core engine and the afterburner. There was no damage to the pre-cooler or the core engine at the end of the experiment. The engine starting sequence for the Mach 4, direct-connect experiment was confirmed.

\section{Design Features of Pre-Cooled Turbojet Engine}

Figure 2 is an external view of the pre-cooled turbojet engine [6]. The engine consisted of a variable-geometry air intake, pre-cooler, core engine, afterburner, and variablegeometry exhaust nozzle. The engine size was determined by the capacity of the Ramjet Engine Test Facility (RJTF) [7] at the JAXA Kakuda Space Center.

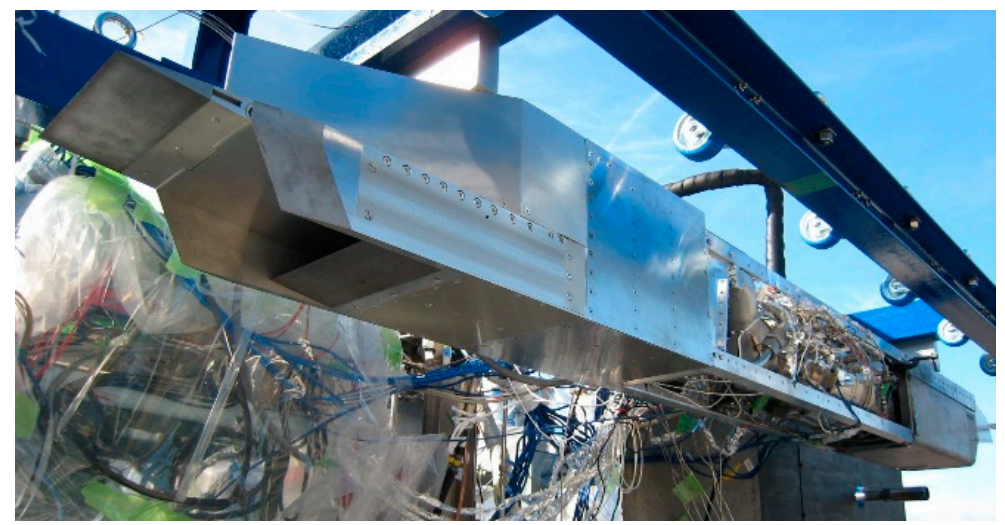

Figure 2. Pre-cooled turbojet engine.

Table 1 summarizes the design features of the engine. The intake was made of a nickel alloy to handle Mach 5 flight conditions. The pre-cooler was a heat exchanger with a counter-flow shell and tube, made of a thin stainless-steel tube with $2 \mathrm{~mm}$ in diameter chosen for its light weight. The casing was also made of a nickel alloy.

Table 1. Specifications of pre-cooled turbojet.

\begin{tabular}{ccc}
\hline Item & Value & Unit \\
\hline Length & 2.7 & $\mathrm{~m}$ \\
Width & 0.23 & $\mathrm{~m}$ \\
Rotation Speed & 80000 & $\mathrm{rpm}$ \\
Air Flow Rate & 1.0 & $\mathrm{~kg} / \mathrm{s}$ \\
Turbine Inlet Temperature & 1223 & $\mathrm{~K}$ \\
Afterburner Temperature & 2073 & $\mathrm{~K}$ \\
\hline
\end{tabular}

The core engine was a one-spool turbojet with a design rotation speed of $80000 \mathrm{rpm}$ and a pressure ratio of 6 . The compressor air mass flow rate at the design point was $1.0 \mathrm{~kg} / \mathrm{s}$. The compressor was made of titanium alloy to endure the stress at the nominal rotation speed. The main combustor and the turbine were both made of a nickel alloy. 
The combustion temperature of the main combustor was limited to a maximum of $1223 \mathrm{~K}$ because the turbine did not have cooling holes. The casing of the core engine was made of stainless steel.

The regenerative cooling part of the variable-geometry nozzle was made of a nickel alloy, and the movable throat and external nozzle were made of stainless steel. The fuel injector of the afterburner was upstream of the exhaust nozzle, and the nozzle cowl was made of $\mathrm{C} / \mathrm{C}$ composite material impregnated with silicone.

\section{Experimental Setup}

The combustion experiment was assembled in the JAXA Noshiro Rocket Testing Center. Figure 3 shows the experimental setup.

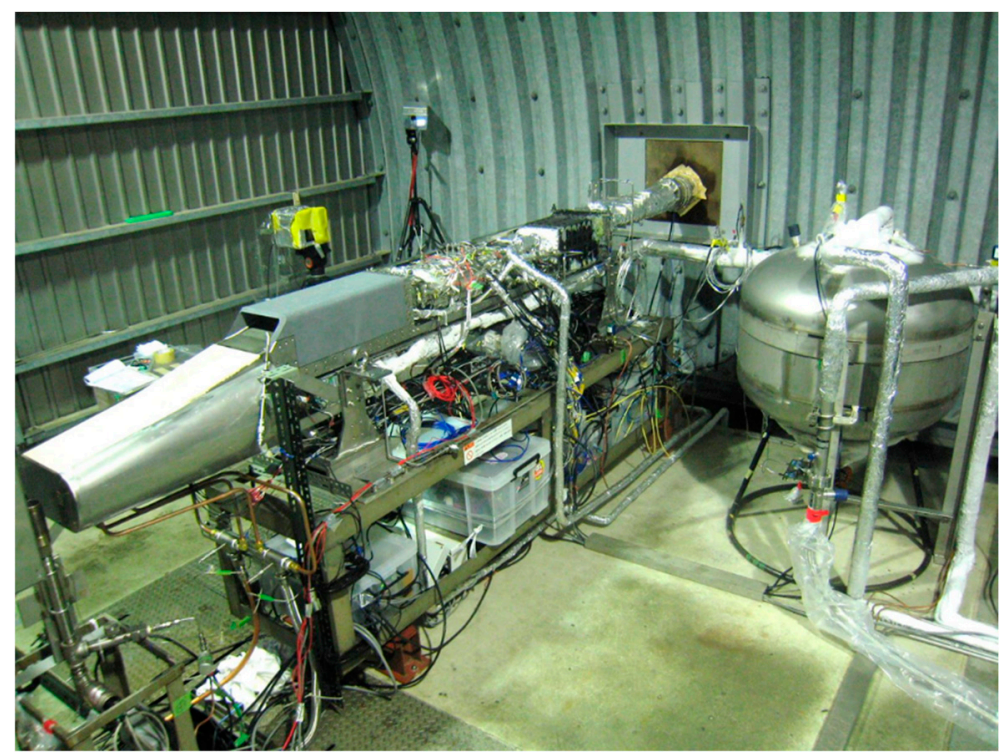

(a)

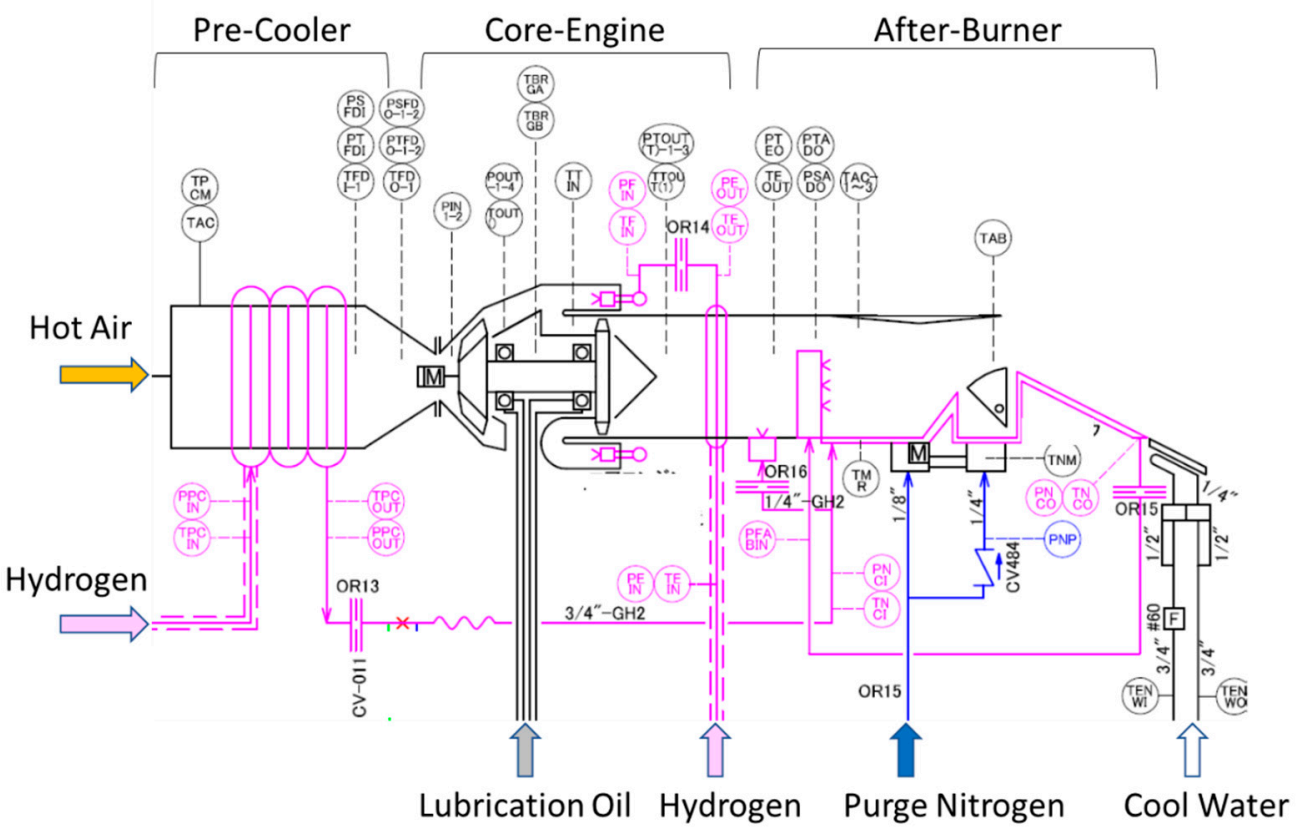

(b)

Figure 3. Experimental setup. (a) External view. (b) Flow diagram. 
The air intake was not used in this setup. The inlet of the pre-cooler was connected directly to the hot air supply, which generated the hot air that simulated the pressure and temperature conditions at the inlet of the pre-cooler. The air was heated by a heat exchanger, which burned combustion gas with propane and air. The oxygen fraction of the air did not change during the heat exchange process.

The fuel tank was filled with liquid hydrogen from an external container; then, it was supplied to the engine by pressurizing the tank using hydrogen gas. After the fuel passed through the pre-cooler and regenerative cooling channel of the variable-geometry nozzle, it was injected into the afterburner. Fuel-rich combustion was selected to attain deep cooling by the pre-cooler. Helium gas supplied from an external tank was used to purge the fuel.

Liquid hydrogen was also supplied to the core engine. The starting sequence of the core engine using liquid hydrogen was investigated using a low-pressure chamber simulating high-altitude conditions. Fuel was supplied under supercritical conditions to avoid hard vaporization in the fuel supply system.

Temperatures inside the engine were measured using thermocouples. Type $\mathrm{K}$ thermocouples were used under $1000 \mathrm{~K}$, and type B thermocouples were used above $1000 \mathrm{~K}$ in the afterburner.

Pressures inside the engine were measured using pressure scanners with temperature compensation capabilities. The maximum pressure range was $700 \mathrm{kPa}$, and the uncertainty was $0.05 \%$ of the maximum range.

The thrust of the engine was not measured in this experiment.

\section{Experimental Methodology}

The experimental cases are shown in Table 2. The temperature was calculated based on the flight trajectory analysis of Mach 4 and a dynamic pressure of $50 \mathrm{kPa}$, with a simulated altitude of $21.3 \mathrm{~km}$. The temperature at Mach 4 was $900 \mathrm{~K}$. The pressure was set to $0.37 \mathrm{MPa}$, higher than the actual pressure at the pre-cooler inlet.

Table 2. Experimental cases.

\begin{tabular}{cccccc}
\hline Case & Unit & $\mathbf{1}$ & $\mathbf{2}$ & $\mathbf{3}$ & $\mathbf{4}$ \\
\hline Simulated Mach Number & & - & 3.4 & 3.4 & 4.0 \\
Total Pressure & $\mathrm{MPa}$ & 0.37 & 0.37 & 0.37 & 0.37 \\
Total Temperature & $\mathrm{K}$ & 288 & 720 & 720 & 900 \\
Pre-Cooler & & & On & On & On \\
Core Engine & & On & On & On & On \\
Afterburner & & 4 & 2 & On & On \\
Number of Experiments & & 4 & & 1 \\
\hline
\end{tabular}

Case 1 was an experiment on only the core engine. The main burner fuel flow rate was controlled, so that the main burner temperature did not exceed the design limit. The mechanical rotation speed was limited to $80000 \mathrm{rpm}$, which is the design speed.

In Case 2, hot air, simulating Mach 3.4 conditions, was supplied to the engine. Liquid hydrogen was provided to both the pre-cooler and the core engine. The fuel supplied to the pre-cooler was discharged to the vent stack without combustion.

In Case 3, the fuel was supplied to the pre-cooler and the afterburner. High-temperature combustion occurred in the afterburner. The simulated flight speed was Mach 3.4.

In Case 4, the simulated flight speed was Mach 4.

The experimental sequence is as follows:

1. The high-temperature air supply facility was started.

2. Liquid hydrogen fuel was supplied from the container to the fuel tank.

3. Oil misting for bearing lubrication and cooling was supplied.

4. Purging nitrogen gas was supplied to the actuator box of the variable-geometry nozzle.

5. The exit torch burner was ignited. 
6. The fuel tank was pressurized by helium gas.

7. The ignition plug was started.

8. Hot air and liquid hydrogen were supplied to the engine simultaneously and ignited.

9. The ignition plug was stopped.

10. The rotation was accelerated by the windmill effect and turbine power.

11. Liquid hydrogen fuel supply was stopped and purged by helium gas.

12. The tank pressure was reduced.

13. Oil misting and purging nitrogen gas supply were stopped.

\section{Experimental Results}

Stable engine operation was confirmed under the test conditions of Table 2.

In Case 1, the engine operated with the restricted main burner temperature. The outer shell vibration was minimized by modifying the direction of the pre-compression of bearings. The rotation speed was at $90 \%$.

In Case 2, stable engine operation was attained at Mach 3.4. This case was conducted with a roof because there was no combustion at the afterburner. Liquid hydrogen was supplied to the pre-cooler and the core engine.

In Case 3, liquid hydrogen was supplied to the pre-cooler and the afterburner. There was an igniter and pilot fuel port upstream of the afterburner. However, the pilot fuel was not ignited, and the exit torch burner ignited the fuel. Liquid hydrogen fuel was supplied to the core engine after the afterburner ignited.

In Case 4, liquid hydrogen was supplied simultaneously to the pre-cooler, afterburner, and core engine. Fuel at the afterburner ignited because combustion the core engine started, and the temperature at the inlet of the afterburner was high enough for self-ignition. Figure 4 is an external view of the setup for Case 4.

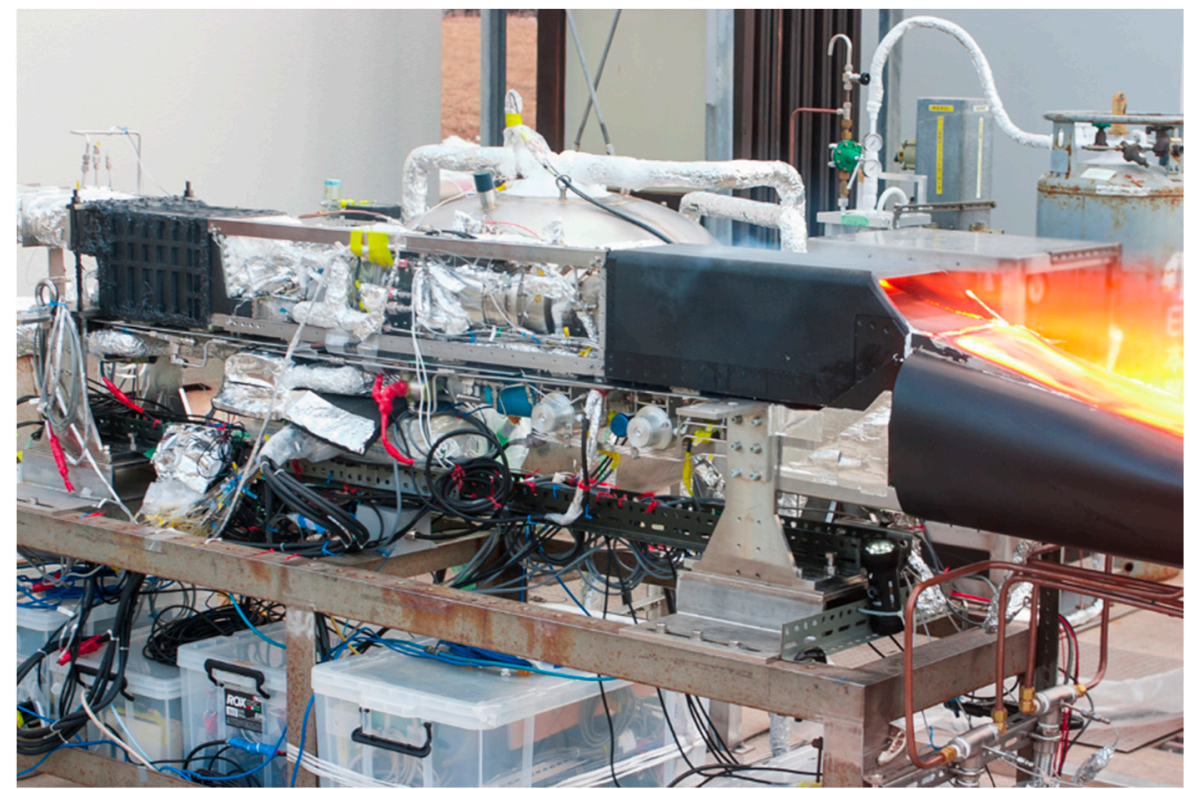

Figure 4. External view of setup (Case 4).

The test time was limited to $20 \mathrm{~s}$ to check for damage to the afterburner after each experiment under the same conditions. This paper describes the results of Case 4 .

\subsection{Rotation Speed}

Figure 5 shows the experimental result of rotation speed. Rotation speed was measured using gap sensors installed on the core engine casing. 


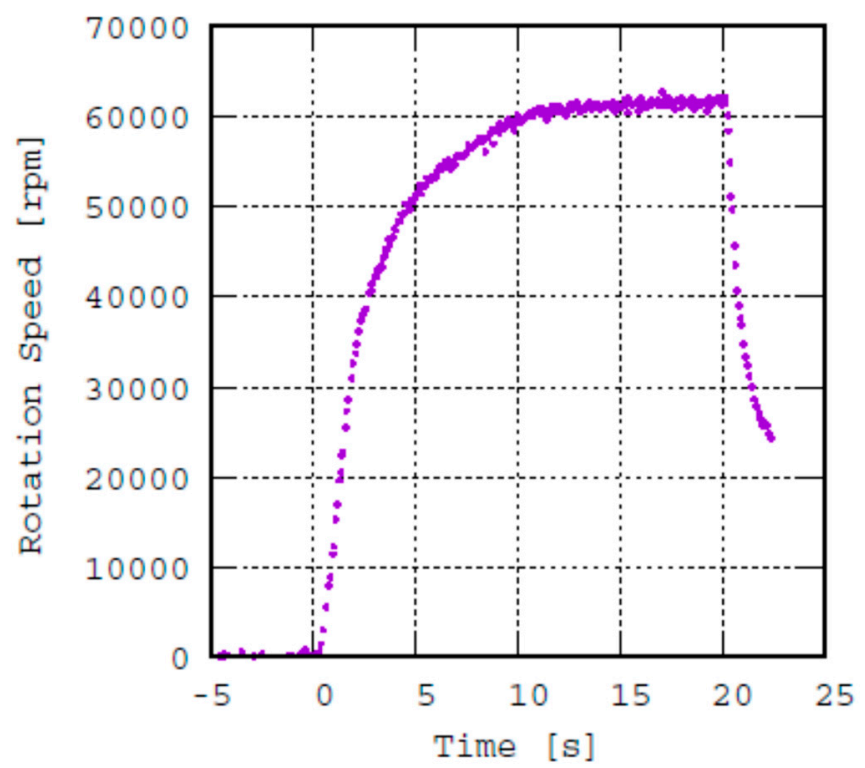

Figure 5. Rotation speed.

At $0 \mathrm{~s}$, the rotation was accelerated by the windmill effect and turbine power by the combustion gas of the main burner. The rotation speed reached $60000 \mathrm{rpm}$ at $10 \mathrm{~s}$. Then, the speed decreased to $20 \mathrm{~s}$. The air supply and fuel supply were stopped at this point.

\subsection{Equivalence Ratio and Combustion Temperature}

Figure 6 shows the time history of the equivalence ratio. The equivalence ratio at the afterburner was 2.2, and the ratio at the main burner was 0.3 . The fuel flow of the afterburner was measured by a turbine flow meter. The fuel-rich operation was selected for the afterburner for a large pre-cooling effect. The fuel flow rate of the main burner was calculated using the upstream pressure at the choke orifice in the supply line. Fuel-lean combustion was selected for the main burner. The fuel supply started at $0 \mathrm{~s}$, and the equivalence ratios became nearly constant at $10 \mathrm{~s}$.

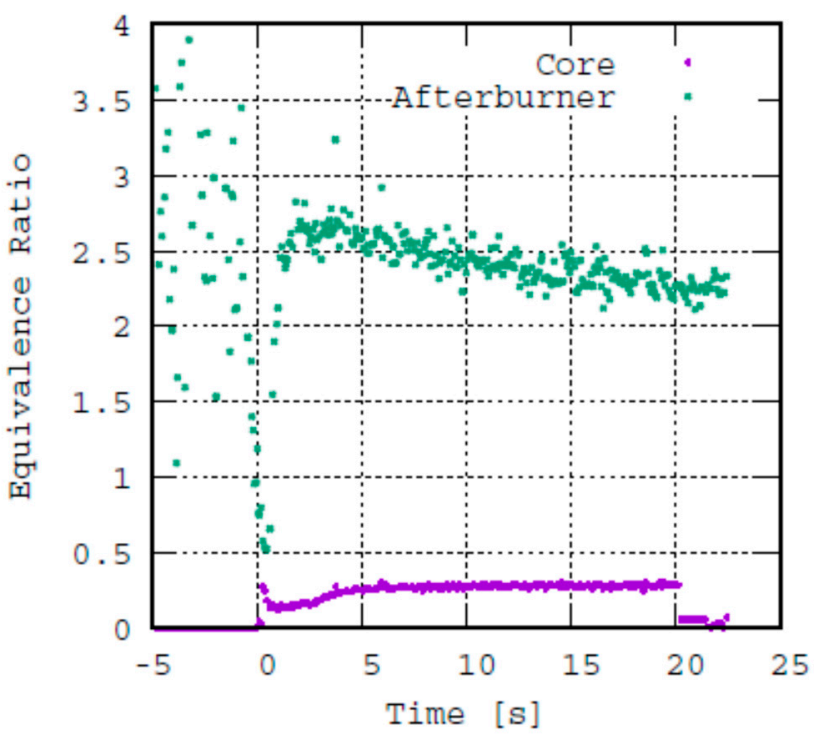

Figure 6. Equivalence ratio.

Fuel injection at the main burner and the afterburner was started at $0 \mathrm{~s}$. The main burner's fuel flow rate was controlled to operate the engine within a limited range of turbine inlet temperatures. The fuel control valve was chilled before the experiment by 
blowing a small amount of supercritical hydrogen fuel through it. The fuel flow rate increased as the flow control valve was opened.

Figure 7 shows the time history of the air temperature at the turbine inlet and exit. The inlet temperature gradually increased and reached $1200 \mathrm{~K}$, nearly the design turbine inlet temperature, at $20 \mathrm{~s}$.

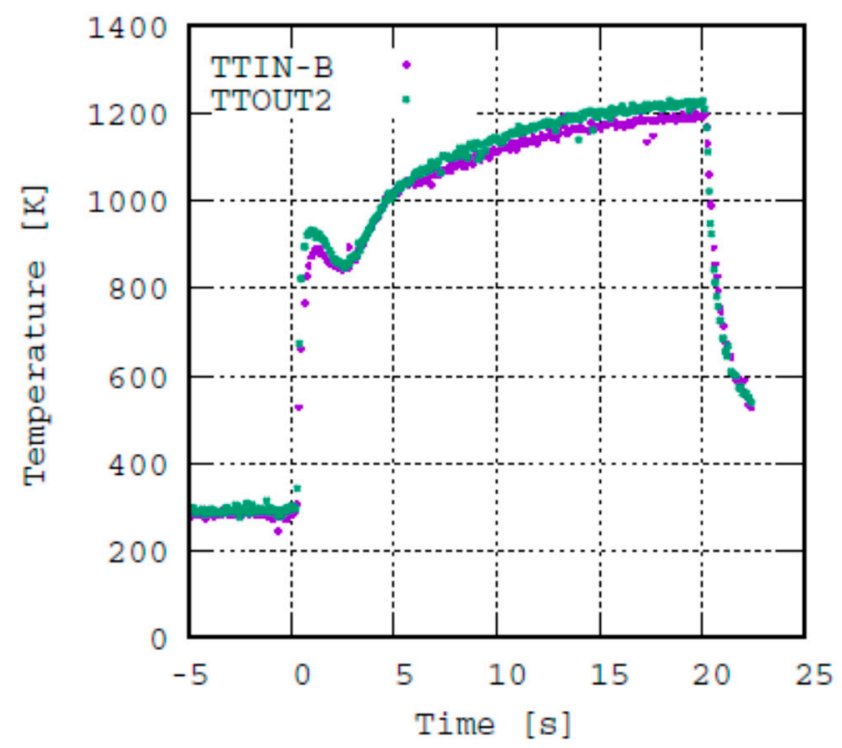

Figure 7. Air temperature at turbine inlet and exit.

Figure 8 shows the time history of temperature at the afterburner exit. The temperature reached $1900 \mathrm{~K}$ at $5 \mathrm{~s}$, gradually increasing to $2000 \mathrm{~K}$ at $20 \mathrm{~s}$. These values are a little lower than the design limit.

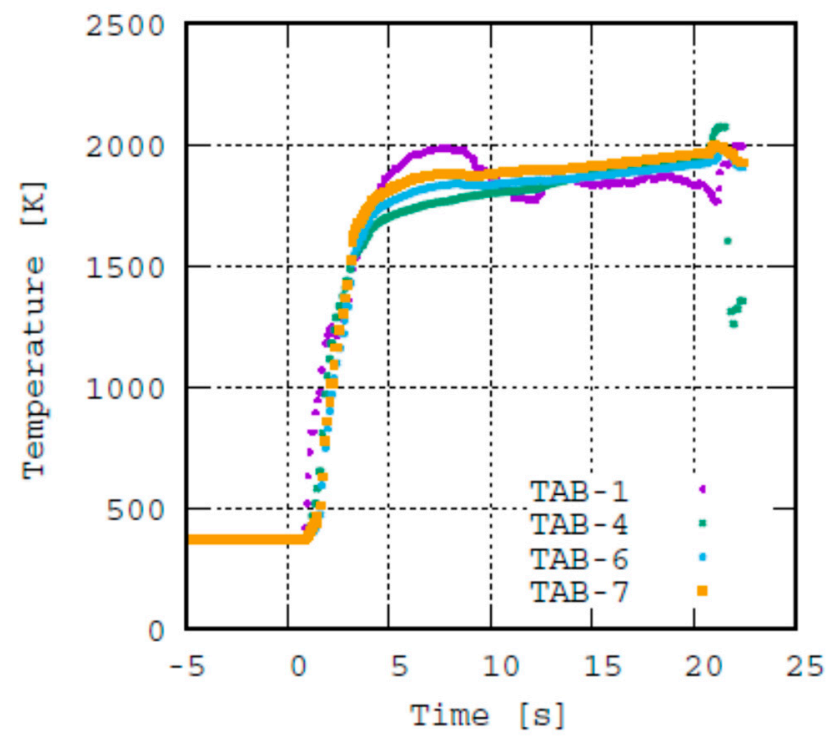

Figure 8. Air temperature at afterburner exit.

The temperature at the exit of the variable-geometry nozzle (TAB-1) rose before the other temperatures, demonstrating that the ignition occurred at the exit torch burner. It was confirmed by a follow-up experiment of the pilot burner that the local equivalence ratio of the pilot burner was below the ignition limit. 


\subsection{Temperature at Pre-Cooler}

Figure 9 shows the time history of air temperature at the inlet of the pre-cooler. There were five measurement points along the airstream. The temperature gradually increased because the heat exchange capacity was small for that airflow rate. The temperature rose to $900 \mathrm{~K}$, which corresponds to Mach 4 flight conditions, at $20 \mathrm{~s}$.

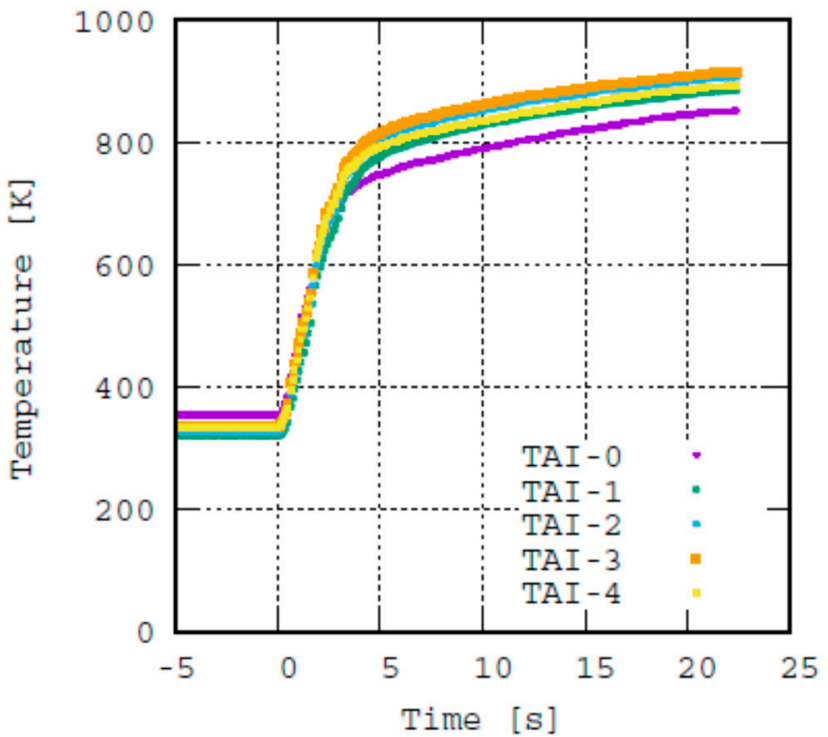

Figure 9. Air temperature at pre-cooler inlet.

Figure 10 shows the time history of air temperature at the pre-cooler exit. The temperature also increased gradually. There was a temperature distortion from $390 \mathrm{~K}$ to $470 \mathrm{~K}$ at $20 \mathrm{~s}$. The average temperature was around $430 \mathrm{~K}$. The temperature decrease at the pre-cooler was $470 \mathrm{~K}$. High stress due to the large temperature gradient was estimated by structural analysis near the fuel manifold. However, there was no damage to the part, as expected.

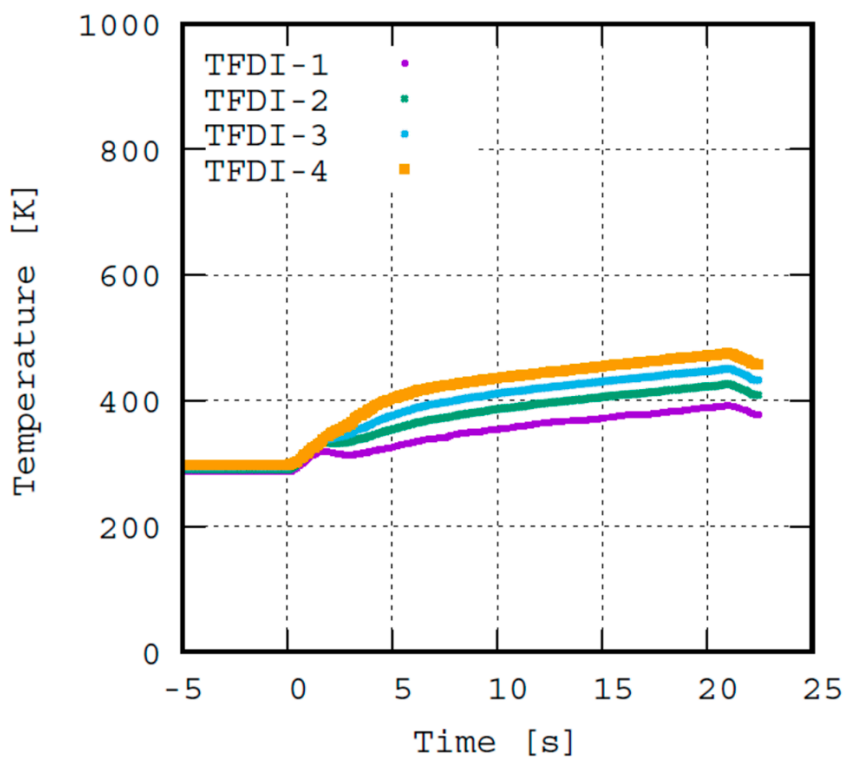

Figure 10. Air temperature at pre-cooler exit. 


\subsection{Heat Exchange Performances}

Figure 11 shows the time history of fuel temperature at the pre-cooler. The supply pressure of hydrogen was $2 \mathrm{MPa}$. The pre-cooler inlet temperature (TPCIN) was $40 \mathrm{~K}$ at $2 \mathrm{~s}$, which indicated that supercritical hydrogen reached the pre-cooler inlet at $2 \mathrm{~s}$. The hydrogen flow inside the heat exchange tube was estimated as turbulent flow because the Reynolds number was $5.7 \times 10^{5}$. The convective heat transfer coefficient was $9.2 \mathrm{~kW} / \mathrm{m}^{2} \mathrm{~K}$. The pre-cooler exit temperature (TPCOUT) was $480 \mathrm{~K}$. The absorbed heat was utilized to increase thrust at the exhaust nozzle.

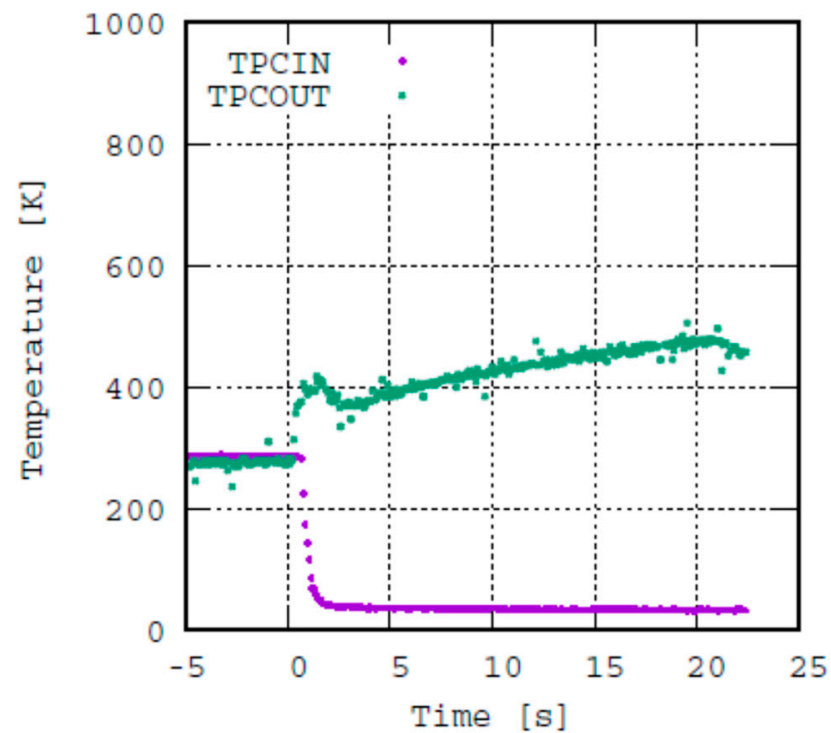

Figure 11. Fuel temperature at pre-cooler.

Figure 12 shows the fuel temperature at the evaporator. The evaporator increased the temperature of supercritical hydrogen, and the hydrogen was supplied to the main burner. The evaporator inlet temperature (TEIN) was near $80 \mathrm{~K}$ at $5 \mathrm{~s}$. The evaporator exit temperature (TEOUT) reached $600 \mathrm{~K}$ by $20 \mathrm{~s}$. The fuel flow rate was reduced by the temperature rise of hydrogen, which has a large heat capacity.

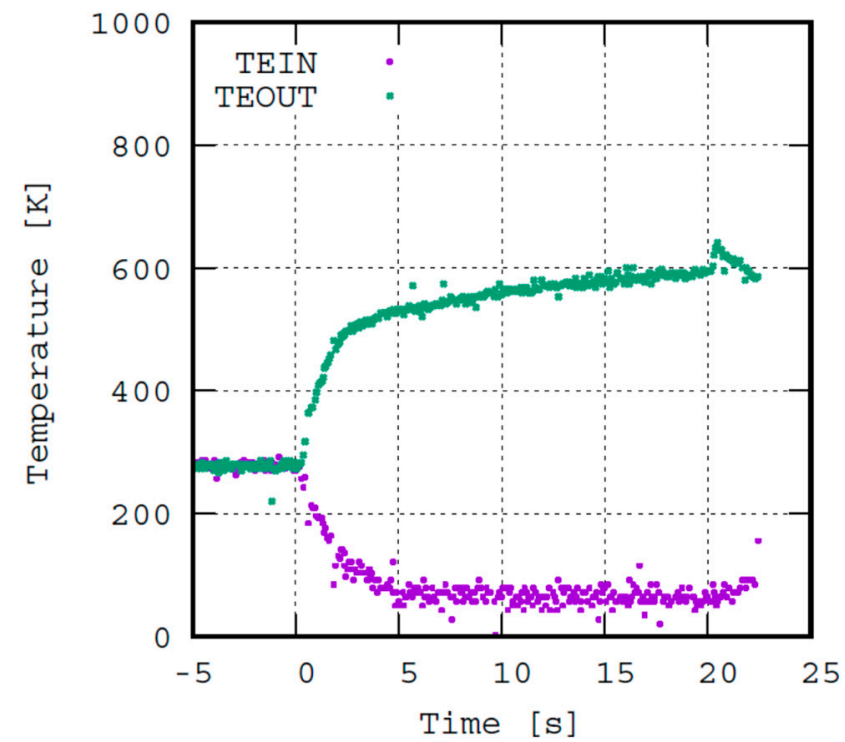

Figure 12. Fuel temperature at fuel evaporator. 


\subsection{Pressure Decrease in the Pre-Cooler}

Figure 13 shows the time history of the gauge pressures at the inlet of the pre-cooler. The pre-cooler inlet gauge pressure (PTAI) was $180 \mathrm{kPa}$ at $20 \mathrm{~s}$. Figure 14 shows the time history of the gauge pressures at the exit of the S-shaped duct, which is downstream of the pre-cooler. The pre-cooler exit gauge pressure (PTFDO) was $170 \mathrm{kPa}$ at $20 \mathrm{~s}$. The pressure decrease was $10 \mathrm{kPa}, 3.6 \%$ of the absolute pressure.

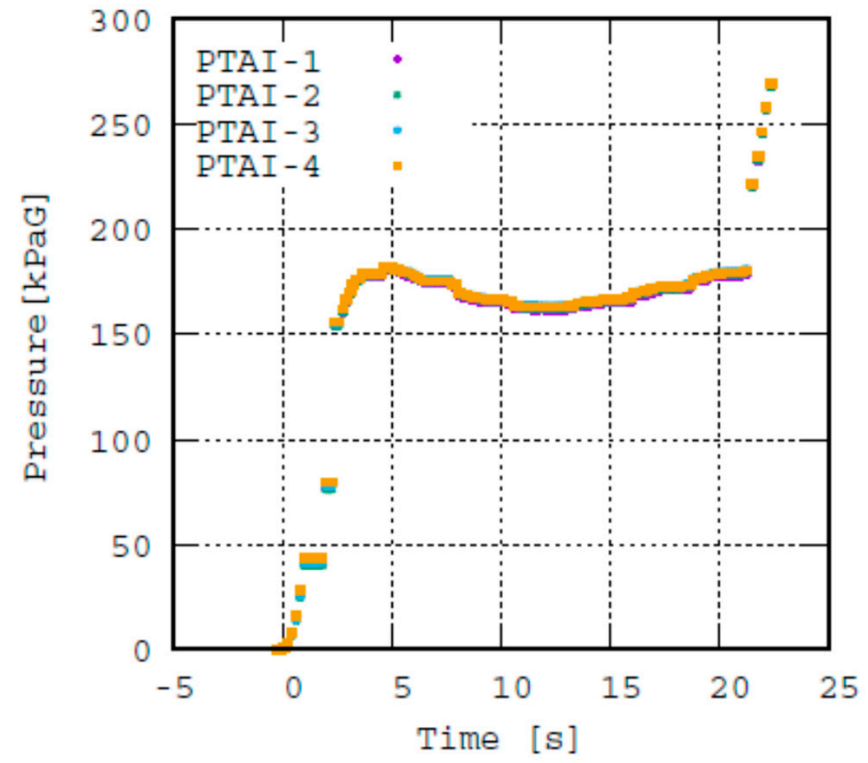

Figure 13. Pressure at the inlet of pre-cooler.

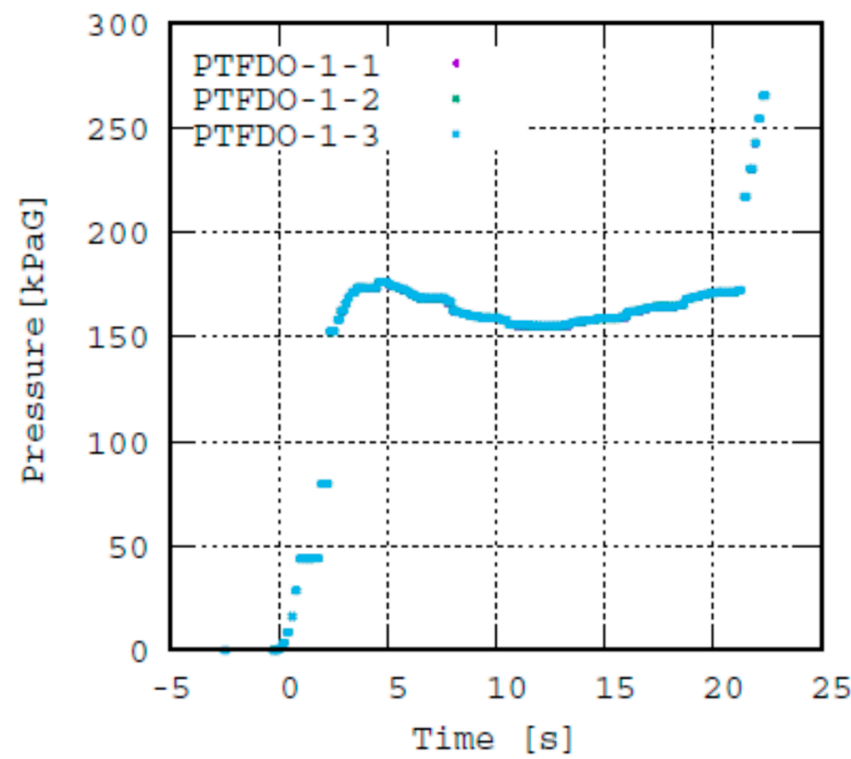

Figure 14. Pressure at the exit of pre-cooler.

\subsection{Pressure Ratio of Compressor and Turbine}

Figure 15 shows the time history of pressure ratios. The compressor pressure ratio was 0.9 from $0 \mathrm{~s}$ to $2.5 \mathrm{~s}$, indicating that the compressor was operating as a windmill turbine. The pressure ratio rose above 1.2 at around $3 \mathrm{~s}$, which means the compressor started compression. The pressure ratio was 2.2 at $10 \mathrm{~s}$. The turbine pressure ratio increased gradually from $0 \mathrm{~s}$ to $10 \mathrm{~s}$. The pressure ratio was around 1.8 at $10 \mathrm{~s}$. 


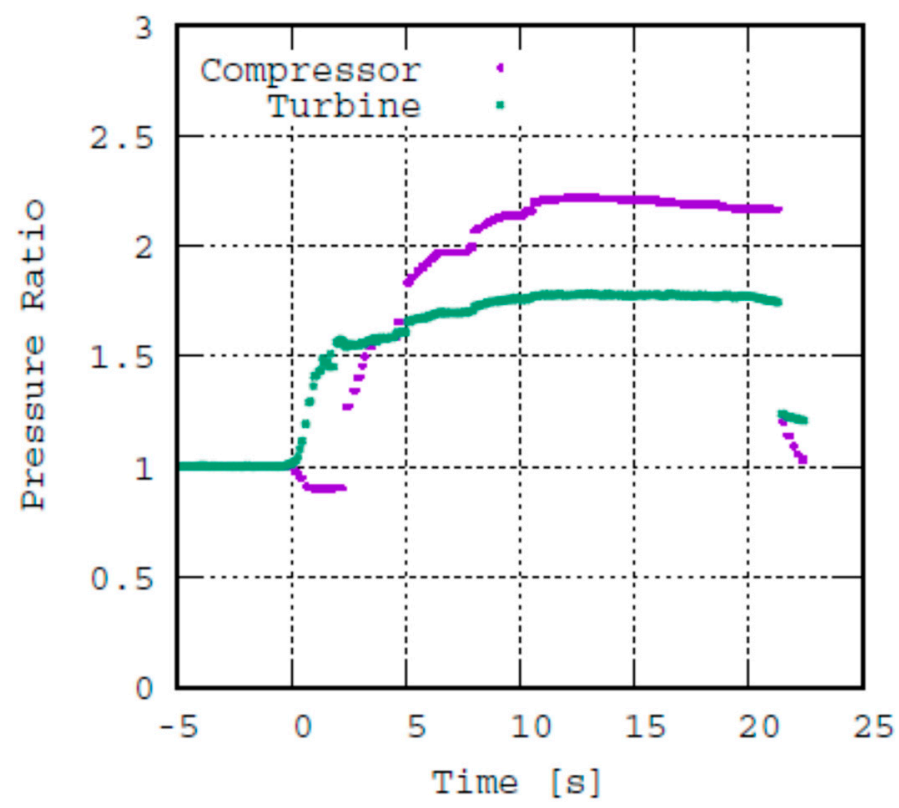

Figure 15. Pressure ratio of compressor and turbine.

\section{Conclusions}

A Mach 4 simulated experiment of the pre-cooled turbojet engine was conducted using liquid hydrogen. As a result, the following results were obtained.

- $\quad$ The starting sequence of the engine components was confirmed under Mach 4 simulated conditions using liquid hydrogen fuel;

- There was no damage to the rotating parts of the core engine due to the pre-cooling effect by the end of the experiment;

- Stable fuel-lean combustion at the main burner and stable fuel-rich combustion at the afterburner were obtained as planned;

- The temperature decrease in the airflow from $900 \mathrm{~K}$ to $430 \mathrm{~K}$ was obtained at the pre-cooler;

- Temperature increases in supercritical hydrogen were obtained at the pre-cooler and fuel evaporator as planned;

- $\quad$ The compressor pressure ratio of 2.2 and turbine pressure ratio of 1.8 were obtained under simulated Mach 4 flight conditions.

Author Contributions: Conceptualization, H.T.; methodology, K.H., H.T.; fabrication, M.H.; software, H.K.; vibration measurement, D.M., S.N.; formal analysis, H.T.; writing, H.T. All authors have read and agreed to the published version of the manuscript.

Funding: This research received no external funding.

Acknowledgments: This research was conducted as a basic research of Japan Aerospace Exploration Agency (JAXA). The basic research budget was approved by the Ministry of Education, Culture, Sports, Science and Technology (MEXT) in Japan. The authors acknowledge the contribution of the following organizations: ASIRI, Concepts NREC, INC engineering, the University of Tokyo, Tokyo University of Science, and Waseda University.

Conflicts of Interest: The authors declare no conflict of interest.

\section{Nomenclature}

CORE Core Engine

TTIN Air Temperature at Turbine Inlet

TTOUT Air Temperature at Turbine Outlet 


$\begin{array}{ll}\text { TAB } & \text { Air Temperature at Afterburner } \\ \text { TAI } & \text { Air Temperature at Pre-cooler Inlet } \\ \text { TFDI } & \text { Air Temperature at Pre-cooler Outlet } \\ \text { TPCIN } & \text { Hydrogen Temperature at Pre-cooler Inlet } \\ \text { TPCOUT } & \text { Hydrogen Temperature at Pre-cooler Outlet } \\ \text { TEIN } & \text { Hydrogen Temperature at Evaporator Inlet } \\ \text { TEOUT } & \text { Hydrogen Temperature at Evaporator Outlet } \\ \text { TPCIN } & \text { Hydrogen Temperature at Pre-cooler Inlet } \\ \text { PTAI } & \text { Air Pressure at Pre-cooler Inlet } \\ \text { PTFDO } & \text { Air Pressure at Pre-cooler Outlet }\end{array}$

\section{References}

1. Taguchi, H.; Kobayashi, H.; Kojima, T.; Ueno, A.; Imamura, S.; Hongoh, M.; Harada, K. Research on hypersonic aircraft using pre-cooled turbojet engines. Acta Astronaut. 2012, 73, 164-172. [CrossRef]

2. Marshall, L.A. Overview with Results and Lessons Learned of the X-43A Mach 10 Flight. In Proceedings of the AIAA 13th International Space Planes and Hypersonic Systems and Technologies Conference, AIAA-2005-3275, Capua, Italy, 16-20 May 2005.

3. Japan Aerospace Exploration Agency. JAXA Long Term Vision-JAXA2025; Japan Aerospace Exploration Agency: Maruzen, Japan, 2005.

4. Taguchi, H.; Futamura, H.; Yanagi, R.; Maita, M. Analytical Study of Pre-Cooled Turbojet Engine for TSTO Spaceplane. In Proceedings of the AIAA/NAL-NASDA-ISAS 10th International Space Planes and Hypersonic Systems and Technologies Conference, AIAA 2001-1838, Kyoto, Japan, 24-27 April 2001.

5. $\quad$ Fujita, K.; Sawai, S.; Kobayashi, H.; Tsuboi, N.; Taguchi, H.; Kojima, T.; Okai, K.; Sato, T.; Miyaji, K. Precooled Turbojet Engine Flight Experiment using Balloon-based Operation Vehicle. Acta Astronaut. 2006, 59, 263-270. [CrossRef]

6. Taguchi, H.; Sato, T.; Kobayashi, H.; Kojima, T.; Okai, K.; Fujita, K. Design Study on a Small Pre-Cooled Turbojet Engine for Flight Experiments. In Proceedings of the 13th AIAA/CIRA International Space Planes and Hypersonic System and Technologies Conference, AIAA 2005-3419, Capua, Italy, 16-20 May 2005.

7. Yatsuyanagi, N.; Chinzei, N.; Mitani, T.; Wakamatsu, Y.; Masuya, G.; Iwagami, S.; Endo, M.; Hanus, G. Ramjet Engine Test Facility (RJTF) in NAL-KRC, JAPAN. In Proceedings of the 8th AIAA International Space Planes and Hypersonic Systems and Technologies Conference, AIAA-98-1511, Norfolk, VA, USA, 27-30 April 1998. 